\title{
Hodgkin Lymphoma in a Child Presenting as HLH (Haemophagocytic Lymphohistiocytosis)-EBV is Central to Both Entities: A Case Report and Review of Literature
}

\author{
Asma Danish ${ }^{1, *}$, Zainab Sharif ${ }^{2}$, Saima Munzir ${ }^{3}$, Tahir Sultan Shamsi ${ }^{1}$ \\ ${ }^{1}$ Department of Clinical Hematology, National Institute of Blood Disease \& Bone Marrow Transplantation, Karachi, Pakistan. \\ ${ }^{2}$ Department of Pediatric Hematology, National Institute of Blood Disease and Bone Marrow Transplantation, Karachi, Pakistan. \\ ${ }^{3}$ Department of Clinical Genetics \& Genomics, National Institute of Blood Disease \& Bone Marrow Transplantation,
}

Karachi, Pakistan.

\begin{abstract}
HLH is a rare life threatening systemic disease resulting from unregulated immune activation presenting with diverse clinical manifestations and etiologies. While Primary or familial HLH is a relatively common occurrence in infants and young children, secondary HLH due to infections, malignancy, rheumatologic and autoimmune disorders is infrequent and carries a grave prognosis owing to delayed or misdiagnosis. Albeitits rarity in children, EBV infection remains the leading cause of both Hodgkin's lymphoma and HLH worldwide. Additionally, data for simultaneous presence of these three entities at the time of diagnosis is limited. Our report focuses on one such case where a patient's clinical signs and symptoms were non-specific and masked by previous history of idiopathic HLH. After being in remission for 2-3 months patient again relapsed but this time around the etiology was Hodgkin's lymphoma with an underlying EBV infection.
\end{abstract}

Keywords: EBV infection, Hodgkin's lymphoma, Haemophagocytic lymphohistiocytosis, Malignancy, Burkett's lymphoma, T-cell lymphoma.

\section{INTRODUCTION}

Haemophagocytic lymphohistiocytosis (HLH) is a multisystem life threatening disorder delineated by an unrestrained immune response, due to cytokine dysregulation and lymphohistiocytic proliferation [1]. It presents with unique integration of clinical and laboratory features with prolonged high-grade unremitting fever, hepatosplenomegaly, marked hypertriglyceridemia, hypofibnogenemia, hypercytokinemia, and cytopenias [2].

HLH is broadly classified into primary and secondary forms with respective subtypes. Primary or familial HLH is associated with genetic mutations as well as certain hereditary and immunodeficiency syndromes and is more common in infants and young children with a median age of onset of 5.1 months [3]. On the contrary, secondary HLH is associated with infections, autoimmune rheumatological disorders, malignancies, haematopoetic stem cell and organ transplant, and HIV infection and is a more frequent finding in older children and adults [4]. Amongst other causes, malignancy associated HLH, due to its rarity in children and considerable-overlapping symptoms is a challenge not only in the diagnosis but also in its timely management [5].

Although still a rare disease, incidence of HLH is increasing and according to a few recent studies, annual incidence of

*Address correspondence to this author at the Department of Clinical Hematology, National Institute of Blood Disease \& Bone Marrow Transplantation, Karachi, Pakistan. E-mail: asmakarm@hotmail.com
HLH is approximately 1-10 per million children [6]. In the context of malignancy associated HLH in children, however, still there is inconclusive and insufficient data. Certain studies in adults have shown that there is an increasing incidence of HLH being reported in adults with lymphomas seen in up to $20 \%$ patients with B- and T-cell lymphomas, incidence of Hodgkin lymphoma being extremely rare [7].

Epstein Barr virus, a common pathogen with seroprevalence in early childhood of approximately $90 \%$ in developing countries has both a marked predisposition for lymphoid malignant neoplasms specifically Hodgkin and Burkett's lymphoma and is also the most common infectious trigger for HLH $[8,9]$. EBV infection as a co-trigger for HLH is observed in $90 \%$ of Hodgkin lymphoma and approximately $33 \%$ of peripheral T-cell lymphoma [10]. However, concurrent finding of these three entities is extremely rare at the time of diagnosis, more so in young children [11]. Our report focuses on such a rare occurrence and emphasizes the importance of prompt consideration of these three cofactors in the management of any patient with HLH.

\section{CASE REPORT}

A four-year old boy, diagnosed as haemophagocytic lymphohistiocytosis in haematology department 9 month back after laboratory and clinical findings (fever, pancytopenia, splenomegaly, hyperferitinimia, hypofibrinoginoemia, hypertriglycedimia and increased sCD25 marker) currently on maintenance therapy for the 
disease, presented again with complains of fever for 5 days. Pattern of fever was remittent, high grade not associated with any specific symptom relieved by antipyretics. On examination, he was febrile, tachycardiac, pale, with single discrete left sided enlarged lymph node measuring 2 inches in diameter, rubbery, non- tender, mobile and not inflamed. $\mathrm{He}$ had a palpable firm spleen around $5 \mathrm{~cm}$ below anterior axillary line and non-tender firm liver around $3 \mathrm{~cm}$ below right costal margin spanning $12 \mathrm{~cm}$. On admission, his baseline investigations showed bicytopenia; $\mathrm{Hb}$ of $8.6 \mathrm{~g} / \mathrm{dl}$, platelet counts $112 \times 10^{9} / \mathrm{L}$ and absolute neutrophil count of $0.7 \times 10^{9} / \mathrm{L}$. His renal and liver function tests were normal. C-reactive proteins and proclacitonin level were raised; while blood urine and throat cultures were negative. Viral screening by polymerase chain reaction (RQ-PCR) showed EBV 20,713 copies/ml, CMV not detected in serum, while serum ferritin levels $2813 \mathrm{ng} / \mathrm{ml}$, fibrinogen $1.9 \mathrm{~g} / \mathrm{l}$, and triglycerides $293 \mathrm{mg} / \mathrm{dl}$.

Bone marrow aspirate showed marked haemophagocytic activity (Fig. 1). Trephine biopsy showed two focal areas of infiltration with large mononuclear cells; some being bilobed with owl's eye appearance. These large mononuclear cells were CD45 negative and CD30 positive as shown in (Fig. 2a-c). Background lymphocytes were CD20 negative but PAX5 positive. CD68 positive macrophages were in sheets and showed active haemophagocytosis. CD3 positive lymphocytic cells were scattered all along the bone marrow tissue. Findings suggestive of classical Hodgkins lymphoma mixed cellularity subtype along with marked haemophagocytic activity. EBV was also present in marrow with 51copies/ul.

Previously, our patient was diagnosed on the basis of clinical and laboratory features as HLH. His viral screen was negative at that time and bone marrow biopsy also revealed marked haemophagocytic activity but no evidence of lymphoma or EBV. His genetic mutation analysis was done for familial HLH (HPLH1, PRF1, Munc13-4, STX11, STXBP2 genes) and for other recognized genetic causes as Chediak Higashi, Griscelli, Wiskott Aldrich syndrome, SCID, Lysinuric protein intolerance, Hermansky Pudlack, X-linked lymphoproliferative syndrome but no mutation was found.

He was treated using HLH 2004 protocol [12]. He received induction for 2 months with etoposide, dexamethasone and cyclosporine initially. On 7th week of induction he developed seizures with visual impairement. His CSF examination was clear, EEG showed generalized slowing and MRI showed mild supratentorial brain atrophy. However he showed rapid improvement in his symptoms as we stopped cyclosporine and started tacrolimus, which is considered to be less neurotoxic of the two-calcineurin inhibitors. After induction, his disease was in remission on bone marrow examination so his continuation treatment was started and he was currently on this treatment.
So, our patient again presented with HLH relapse (proven by similar positive findings of fever, pancytopenia, splenomegaly, hyperferitinimia, hypofibrinoginoemia, hypertriglycedimia and increased sCD25) marker but this time a secondary cause was elucidated and it was Hodgkin lymphoma concurrently with underlying EBV infection. His chemotherapy using the ABVD protocol for Hodgkin lymphoma has recently commenced and patient's general clinical status has started to improve.

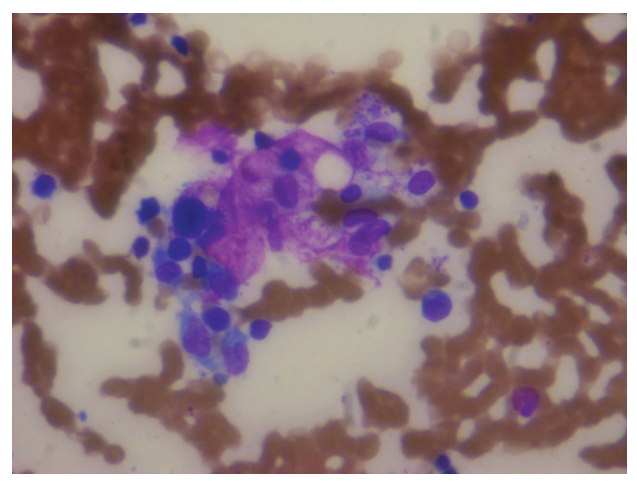

Fig. (1). Bone Marrow Aspirate Showing Hemophagocytosis.

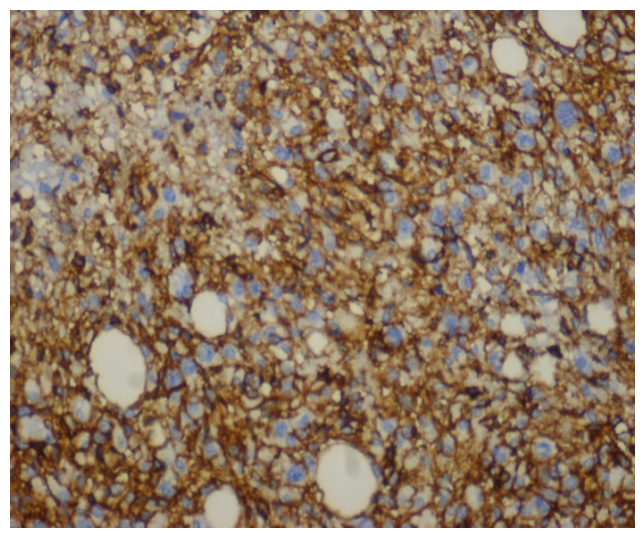

Fig. (2a). CD68 Positive Macrophages.

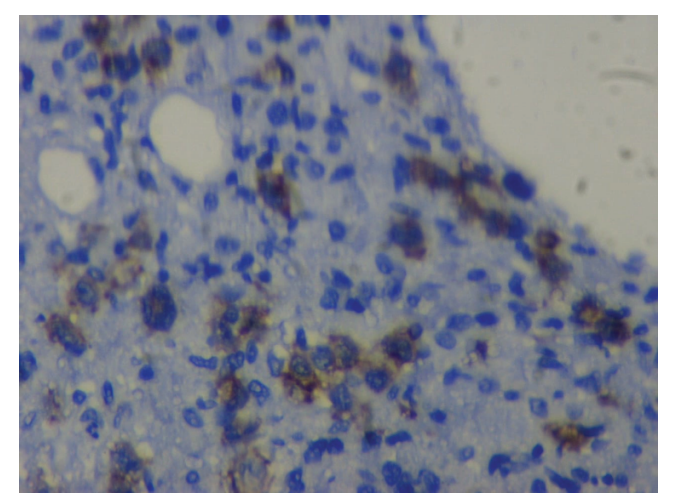

Fig. (2b). CD30 Positive Mononuclear Cells. 


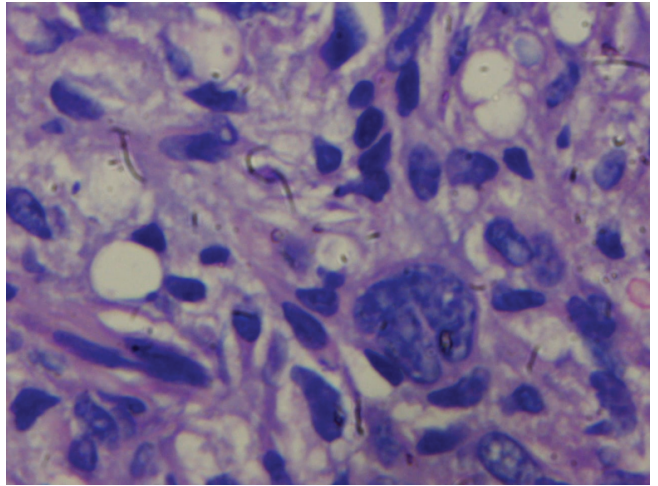

Fig. (2c). Large Cells with Bilobed Nucleus.

\section{DISCUSSION}

Hodgkin lymphoma associated HLH with co-existence of an underlying EBV infection is an extremely rare occurrence in young children and has never been reported. Secondary HLH in young children is mostly associated with infections with EBV being a major pathogen accounting for $40 \%$ of all cases of HLH [13]. Insufficient data has been gathered regarding malignancy associated HLH in children so major published data denotes its occurrence in adults. A large series of studies from 2,197 adult HLH patients have demonstrated that M-HLH accounts for approximately $50 \%$ of adult HLH with $\mathrm{T}$ cell or NK cell lymphoma or leukemia having the highest (35.2\%), and Hodgkin lymphoma having a lower incidence (5.8\%) [14]. These lymphomas are frequently associated with EBV infection, which plays a key role in the pathogenesis of subsequent development of HLH. Hodgkin lymphoma is associated with EBV in $20-80 \%$ of cases, depending on histological subtype [15]. Ménard et al., demonstrated that among 34 patients with Hodgkin's lymphoma and HLH, 32 had positive EBV detected in tumor cells [16].

The EBV latent membrane protein1 (LMP-1) is thought to induce production of high levels of TNF alpha by malignant infected cells, leading to the haemophagocytic process [17]. In the same study done by Menard et al. the histological subtype which they encountered mostly was lymphocyte depleted and mixed cellularity subtype accounting for $85 \%$ of cases. These two subtypes were also associated with bone marrow involvement occurring in $53 \%$ cases which seemed to be a higher incidence than reported earlier [18]. Our patient exhibited both of these factors as it was mixed cellularity type and had significant marrow involvement at the time of diagnosis. They also demonstrated EBV, which was present in about 94\% Hodgkin lymphoma patients with HLH compared to $20-40 \%$ patients without HLH showing a strong correlation. Mixed cellularity subtype of Hodgkin lymphoma is also highly associated with EBV infection [18]. Jarret et al. has studied impact of EBV infection on clinical outcome of Hodgkin lymphoma patients and it presents with a poorer prognosis.
Considering our patient is a young child who was immunosuppressed at the time of recurrence of HLH, he had strong predisposition to EBV infection, which could have been a triggering factor in above sequence of events.

\section{CONCLUSION}

Due to rare incidence in children and obscure signs and symptoms of malignancy there is a high chance that such a rare trilogy of association between a pathogen, malignancy and HLH might be overlooked and easily missed. It is therefore imperative to consider this in the differential diagnosis of children with HLH improving out come in such patients by timely diagnosis and subsequent management.

\section{CONFLICT OF INTEREST}

Declared none.

\section{ACKNOWLEDGEMENTS}

We acknowledge all our fellow colleagues.

\section{REFERENCES}

[1] Henter J-I, Horne A, Aric'o M, et al. HLH-2004: Diagnostic and therapeutic guidelines for hemophagocytic lymphohistiocytosis. Pediatr Blood Cancer 2007; 48(2): 124-31. DOI: $10.1002 /$ pbc. 21039

[2] Henter J-I, Arico M, Egeler RM, et al. HLH-94: A treatment protocol for hemophagocytic lymphohistiocytosis. HLH Study Group of the Histiocyte Society. Med Pediatr Oncol 1997; 28: 342-7.

DOI:10.1002/(SICI)1096-911X(199705)28:5

$<342:$ :AID-MPO3>3.3.CO;2-Y

[3] Erker C, Parker-Murray P, Talano JA. Usual and unusual manifestations of familial hemophagocytic lymphohistiocytosis and Langerhans cell histiocytosis. Pediatr Clin North Am 2017; 64(1): 91-109. doi:10.1016/j. pcl.2016.08.006.

DOI: $10.1016 /$ j.pcl.2016.08.006

[4] Finkielman JD, Grinberg AR, Paz LA, et al. Case report: Reactive hemophagocytic syndrome associated with disseminated strongyloidiasis. Am J Med Sci 1996; 312: 37-9.

DOI: 10.1097/00000441-199607000-00008

[5] Li F, Yang Y, Jin F, et al. Clinical characteristics and prognostic factors of adult hemophagocytic syndrome patients: A retrospective study of increasing awareness of a disease from a single-center in China. Orphanet J Rare Dis 2015; 10: 20. DOI: $10.1186 / \mathrm{s} 13023-015-0224-\mathrm{y}$

[6] Niece JA, Rogers ZR, Ahmad N, Langevin AM, McClain KL. Hemophagocytic lymphohistiocytosis in Texas: Observations on ethnicity and race. Pediatr Blood Cancer 2010; 54: 424-28. DOI: $10.1002 /$ pbc. 22359

[7] Machaczka M, Vaktnas J, Klimkowska M, Hagglund H. 
Malignancy-associated hemophagocytic lymphohistiocytosis in adults: a retrospective population based analysis from a single center. Leuk Lymphoma 2011; 52: 613-9.

DOI: $10.3109 / 10428194.2010 .551153$

[8] Takeuchi K, Tanaka-Taya K, Kazuyama Y, et al. Prevalence of Epstein- Barr virus in Japan: Trends and future prediction. Pathol Int 2006; 56: 112-6. DOI: $10.1111 / \mathrm{j} .1440-1827.2006 .01936 . x$

[9] Wang H, Xiong L, Tang W, Zhou Y, Li F. A systematic review of malignancy-associated hemophagocytic lymphohistiocytosis that needs more attentions. Oncotarge 2017; 8(35): 59977-85. DOI: 10.18632/oncotarget. 19230

[10] Kounami S, Nakayama K, Yoshiyama M, et al. Early onset hemophagocytic lymphohistiocytosis after the start of chemotherapy for advanced neuroblastoma. Pediatr Hematol Oncol 2012; 29: 99-103. DOI: 10.3109/08880018.2011.643529

[11] M'enard F, Besson C, Rinc P, et al. Hodgkin lymphoma associated hemophagocytic syndrome: A disorder strongly correlated with Epstein-Barr virus. Clin Infect Dis 2008; 47(4): 531-4. DOI: 10.1086/590152

[12] Ishii E, Ohga S, Imashuku S, et al. Nation wide survey of hemophagocytic lymphohistiocytosis in Japan. Int J Hematol 2007; 86: 58-65. doi:10.1532/IJH97.07012

DOI: $10.1532 /$ IJH97.07012

[13] Ramos-Casals M, Brito-Zerón P, López-Guillermo A,
Khamashta MA, Bosch X. Adult haemophagocytic syndrome. Lancet 2014; 383: 1503-16.

DOI: $10.1016 / \mathrm{S} 0140-6736(13) 61048-\mathrm{X}$

[14] Hasselblom S, Linde A, Riddel B. Hodgkin's lymphoma, Epstein-Barr virus reactivation and fatal hemophagocytic syndrome. J Intern Med 2004; 255: 289-95.

DOI: $10.1046 / j .0954-6820.2003 .01249 . x$

[15] Ménard F, Besson C, Rincé P, et al. Hodgkinlymphoma-associatedhemophagocyticsyndrome: A disorder strongly correlated with Epstein-Barr virus. Clin Infect Dis 2008; 47: 531-4. DOI: $10.1086 / 590152$

[16] Lay JD, Chuang SE, Rowe M, SuI J. Epstein-Barrviruslatentmembraneprotein-1mediates upregulation of tumor necrosis factor-Ain EBV-infected T cells: Implications for the pathogenesis of hemophagocytic syndrome. J Biomed Sci 2003; 10 : 146-55. DOI: $10.1007 / \mathrm{BF} 02256006$

[17] O'Carroll DI, McKenna RW, Brunning RD. Bone marrow manifestations of Hodgkin's disease. Cancer 1976; 38: 1717-28.

DOI:10.1002/1097-0142(197610)38:4<1717::AID-CNCR2820380445>3.0.CO;2-9

[18] Jarrett RF, Stark GL, White J, et al. Impactof tumor Epstein-Barr virus status on presenting features and outcome in age-defined subgroups of patients with classic Hodgkin lymphoma: A population-based study. Blood 2005; 106: 2444-51. DOI: 10.1182/blood-2004-09-3759 